\title{
Simultaneous Estimation of Atorvastatin and Aspirin in Bulk and Capsule Dosage Form by Chemometric Assisted Spectrophotometric Methods
}

\author{
Keerthisikha Palur ${ }^{1 *}$, Bharathi Koganti ${ }^{2}$, Sreenivasa Charan Archakam¹, Sridhar Chenchugari ${ }^{1}$, Bhavana Nagireddy ${ }^{1}$, Mahesh Babu Devab- \\ haktuni' ${ }^{1}$, Meenakshi Sankranthi ${ }^{1}$ \\ 'Department of Pharmaceutical Analysis, Sri Padmavathi School of Pharmacy, Tiruchanoor, Andhra Pradesh, INDIA. \\ ${ }^{2}$ Institute of Pharmaceutical Technology, Sri Padmavathi MahilaViswaVidyalayam, Tirupati, Andhra Pradesh, INDIA.
}

\begin{abstract}
Objective: To develop the UV-spectrophotometric method and to apply the Chemometric designs to the developed method for the simultaneous estimation of Atorvastatin calcium (ATR) and Aspirin (ASP) in intact capsule dosage form without further extraction. Methods: The UV-Spectrophotometric method was developed by using methanol as solvent for both the drugs and the data generated from the absorption spectra was mined by two Chemometric designs which were based on the principles of linear regression analysis method (LRC) and Crammer's matrix method (CRM). The wavelengths selected for linear regression analysis and crammers'matrix methods were $245 \mathrm{~nm}$ (wavelength of maximum absorption; $\lambda_{\text {max }}$ of ATR) and $275 \mathrm{~nm}$ (wavelength of maximum absorption; $\lambda_{\max }$ of ASP). Results: Both the methods hold good linearity for ATR from $4-20 \mu \mathrm{g} / \mathrm{ml}$ and for ASP from $20-120 \mu \mathrm{g} / \mathrm{ml}$ with regression coefficient values of 0.9999 and 0.9991 respectively. The intraday and inter-day precision was found to be less than $2 \%$ RSD. The percentage recovery was in the range of 100.1-102.65 for Atorvastatin calcium and 99.95-101.15 for Aspirin by both the methods. The percentage assay was found to be 102.52 for ATR and 98.9 for ASP
\end{abstract}

by LRC method and 101.62 for ATR and 98.84 for ASP by CRM method. Conclusion: The developed methods neither require any cumbersome separation procedure nor complex derivatization procedures for the analysis of the two drugs and moreover they are effective in minimizing the errors in analysis, simple and economical.

Key words: Chemometrics, Regression analysis, Cramer's Matrix method, Atorvastatin, Aspirin.

Correspondence :

Keerthisikha Palur,

Department of Pharmaceutical Analysis, Sri Padmavathi School of Pharmacy, Tiruchanoor, Andhra Pradesh, INDIA.

Tel no: +919533559130

E-mail: keerthi8spsp@gmail.com

DOI: 10.5530/jyp.2016.4.19

\section{INTRODUCTION}

Chemometrics is a branch of science that derives data by the application of mathematical and statistical methods, for the extraction of useful information from physical and chemical phenomena involved in a manufacturing process. ${ }^{1-8}$ Chemometrics is used for multivariate data collection and analysis protocols, calibration, process modelling, pattern recognition and classification, signal correction and compression, and statistical process control. In view of the significant problems in the analysis of intricate multicomponent formulations by the conventional analytical methods in UV-spectroscopy and HPLC, Chemometric assisted analytical methods are designed to perform analytical investigation of such complex formulations.

Atorvastatin is chemically known as 7-[2-(4-fluorophenyl)-3-phenyl-4(phenyl Carbamoyl) -5- (propan-2-yl)-1H-pyrrol-1-yl] -3, 5-dihydroxyheptanoate. ${ }^{9}$ It is a selective competitive HMG-CoA reductase inhibitor. It reduces the risk of cardiovascular diseases. The Chemical structure of Atorvastatin was shown in Figure 1.

Aspirin is chemically known as 2-(acetyloxy) benzoic acid. ${ }^{10}$ Acetylsalicylic acid is an analgesic, antipyretic, anti-rheumatic, and anti- inflammatory agent. Acetylsalicylic acid's mode of action as an anti- inflammatory and anti-rheumatic agent may be due to inhibition of synthesis and release of prostaglandins. The Chemical structure of Aspirin was shown in Figure 2. The combination of Atorvastatin and Aspirin is used widely in the treatment of cardiovascular disorders and to lower the cholesterol levels.

Literature survey revealed that very few analytical methods like UVSpectroscopy and HPLC methods were reported and no chemometric method was reported for the analysis of the above said combination. ${ }^{11-23}$ Moreover, most of the proposed methods demand complex extraction procedures for the separation of drugs in to individual components from the dosage form Thus the present study aims to design chemometric assisted spectroscopic methods for the intricate analysis of Atorvastatin and Aspirin without prior separation.

\section{MATERIALS AND METHODS}

\section{Instruments used}

Analytical Balance (Denver, M-220D), UV - Visible Spectrophotometer (Shimadzu-UV 1800), Ultra sonicator (PCI Analytics Ltd.-6.5L) were used in present study.

\section{Data Handling Systems}

UV-Probe 2.3.4 was used for the handling of UV -Visible Spectrophotometer. Algebrator (Ver. 5.0) and Easy Matrix Calculator Pro (Ver. 5.4) were used for resolving the data matrices.

\section{Materials Used}

The working standards of Atorvastatin and Aspirin were procured from Vance \& Health, Pharmaceuticals, Pvt. Ltd, Hyderabad. Commercial formulation of the drugs were purchased from local market. Methanol AR-grade was procured from E. Merck (India) Ltd., Mumbai. Double distilled water was obtained from in-house distillation unit.

\section{Preparation of Solutions}

\section{Preparation of Atorvastatin standard solutions}

$25 \mathrm{mg}$ of Atorvastatin standard was weighed accurately and transferred to a $25 \mathrm{ml}$ standard flask. The standard sample was dissolved using $15 \mathrm{ml}$ 


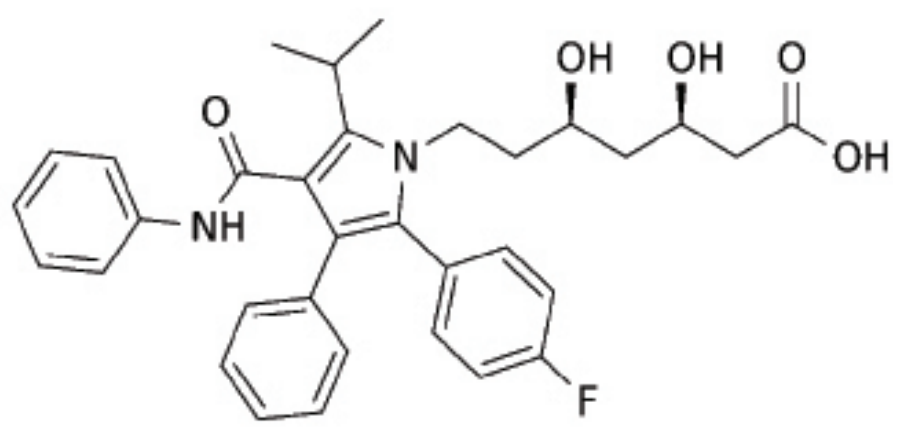

Figure 1: Chemical Structure of Atorvastatin.

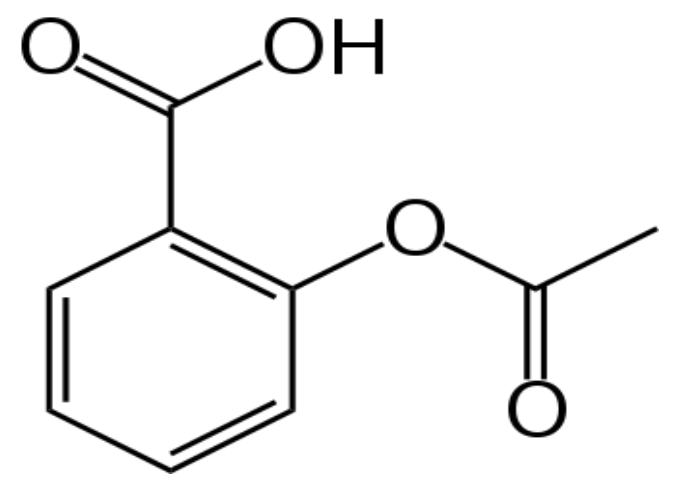

Figure 2: Chemical Structure of Aspirin.

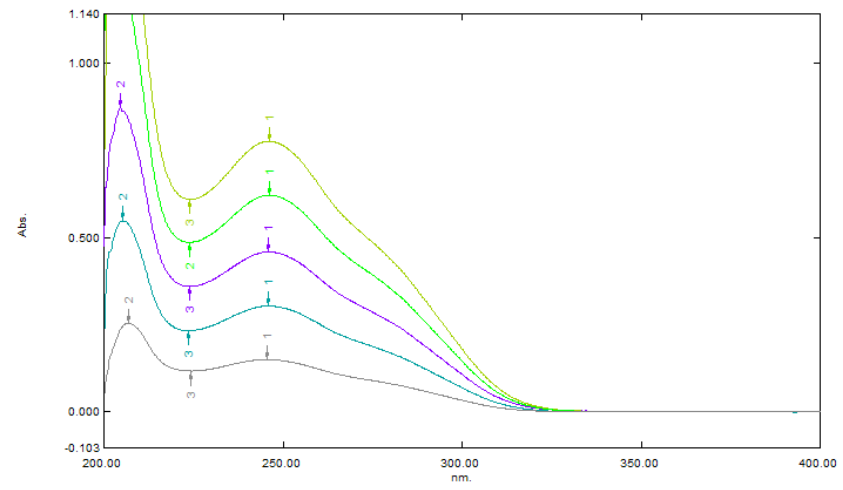

Figure 3: Calibration curve of Atorvastatin $(4-20 \mu \mathrm{g} / \mathrm{ml})$ at $245 \mathrm{~nm}$.

of methanol and made up to the mark with methanol. Further dilutions were made with the methanol to get the required concentrations of 4,8 , 12,16 and $20 \mu \mathrm{g} / \mathrm{ml}$.

\section{Preparation of Aspirin standard solutions}

$10 \mathrm{mg}$ of Aspirin standard was weighed accurately and transferred to a $10 \mathrm{ml}$ standard flask. The standard sample was dissolved using $5 \mathrm{ml}$ of methanol and made up to the mark with methanol. Further dilutions were made with the methanol to get the required concentrations of 20 , $40,60,80,100$ and $120 \mu \mathrm{g} / \mathrm{ml}$.

\section{Preparation of Atorvastatin and Aspirin sample solution}

20 capsules were accurately weighed and triturated. Required quantity of powder equivalent to $10 \mathrm{mg}$ of Atorvastatin and $75 \mathrm{mg}$ of Aspirin was

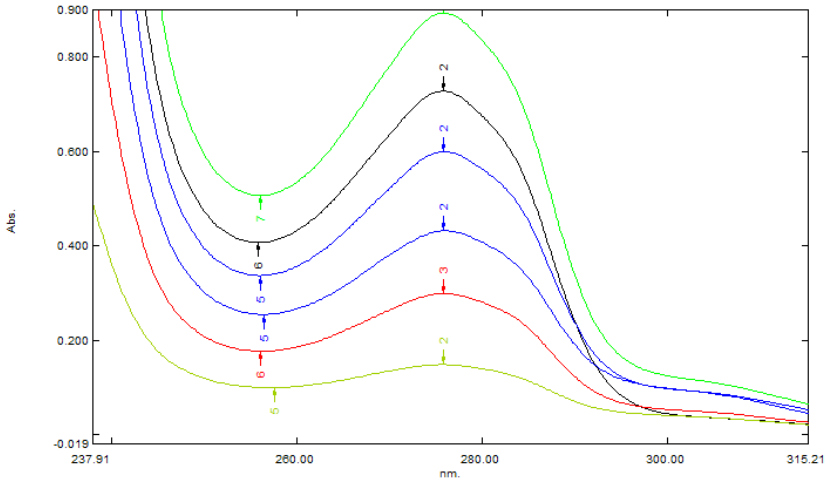

Figure 4: Calibration curve of Aspirin $(20-120 \mu \mathrm{g} / \mathrm{ml})$ at $275 \mathrm{~nm}$.

weighed and transferred into a $10 \mathrm{ml}$ volumetric flask. Required quantity of this stock solution was pipetted into volumetric flask to get $10 \mu \mathrm{g} / \mathrm{ml}$, $75 \mu \mathrm{g} / \mathrm{ml}$ concentrations of Atorvastatin, Aspirin respectively.

\section{Design of Chemometric Models}

Two chemometric models were designed for the developed UV-spectrophotometric method for the simultaneous estimation of Atorvastatin and Aspirin. The first model was based on linear regression equation which includes variables like absorbance, slope and intercept of the calibration curve in the calculation of concentration of the drugs. Second model was based on the molar absorptivity values of the drugs.

\section{Linear Regression Component (LRC) method}

For LRC method, two wavelengths were considered for the analysis of the component mixture [ATR (X), and ASP (Y)]. The two linear regression equations were obtained by using the absorbance measured at two wavelengths against the concentrations of standard solution for each component. The slope values obtained from the linear regression analysis for each component were used for the formation of the matrix set. The wavelengths selected for the analysis were $245 \mathrm{~nm}$ ( $\lambda_{\max }$ of ATR), $275 \mathrm{~nm}$ $\left(\lambda_{\max }\right.$ of ASP).

Equations for the formation of matrix are:

$$
\begin{aligned}
& A_{\text {trutk1 }}=b_{x y} C_{x}+b_{y} C_{y}+a_{y y} \\
& A_{\text {mix } 2}=b_{x 2} C_{x}+b_{y 2} C_{y}+a_{x y 2}
\end{aligned}
$$

Where, $A_{\text {mixl }}, A_{\text {mix } 2}$, are the absorbances of the mixture of $\mathrm{X}, \mathrm{Y}$ analytes at two wavelengths set. $a_{x y 1}, a_{x y 2}$, are the sum of intercepts of the linear regression equation at the two wavelengths. $\mathrm{C}_{\mathrm{x}}$ and $\mathrm{C}_{\mathrm{y}}$ are the concentrations of Atorvastatin and Aspirin. $b_{x 1}, b_{x 2}, b_{y 1}$ and $b_{y 2}$ are the slopes of Atorvastatin and Aspirin at $245 \mathrm{~nm}$ and $275 \mathrm{~nm}$ respectively.

Conversion of equation into matrix form:

$$
\left[\begin{array}{ll}
\text { Amix1- } & \text { axy1 } \\
\text { Amix2- } & \text { axy2 }
\end{array}\right]=\left[\begin{array}{ll}
\text { bx } 1 & \text { by } 1 \\
b x 2 & b y 2
\end{array}\right] \times\left[\begin{array}{l}
C x \\
C y
\end{array}\right]
$$

\section{Cramer's Matrix Method (CRM)}

Molar absorptivity $(\varepsilon)$ values were calculated by using the absorbance measured at $245 \mathrm{~nm}$, and $275 \mathrm{~nm}$ for each compound in the binarymixture. The selected wavelength values were $\lambda_{\text {max }}$ of ATR, and ASP respectively. By using absorptivity $(\varepsilon)$ values, a system of equations with two unknowns in the double mixture have been written as follows:

$$
\mathrm{A}_{\mathrm{m} 245}=\varepsilon_{\mathrm{AT}, 245} \mathrm{C}_{\mathrm{ATR}}+\varepsilon_{\mathrm{ASP}, 245} \mathrm{C}_{\mathrm{ASP}}
$$




$$
\mathrm{A}_{\mathrm{m} 275}=\varepsilon_{\mathrm{ATR}, 275} \mathrm{C}_{\mathrm{ATR}}+\varepsilon_{\mathrm{ASP}, 275} \mathrm{C}_{\mathrm{ASP}}
$$

Where $\mathrm{A}_{\mathrm{m}}$ denotes the absorbance of the binary mixture and $\varepsilon$ represents the values of molar absorptivity for the calculated ATR and ASP respectively at $245 \mathrm{~nm} \& 275 \mathrm{~nm}$. C is the molar concentration of ATR and ASP. The matrix simplifies and solves the system of equations with two unknowns as follows:

$$
\begin{aligned}
& {\left[\begin{array}{l}
\text { Am245 } \\
\text { Am275 }
\end{array}\right]=\left[\begin{array}{ll}
\varepsilon \text { ATR, } 245 & \varepsilon \text { ASP, 245 } \\
\varepsilon \text { ATR,275 } & \varepsilon \text { ASP, 275 }
\end{array}\right] x\left[\begin{array}{l}
\text { CATR } \\
\text { CASP }
\end{array}\right]} \\
& \Delta=\left[\begin{array}{ll}
\varepsilon \text { ATR }, 245 & \varepsilon \text { ASP, } 245 \\
\varepsilon \text { ATR, } 275 & \varepsilon \text { ASP, 275 }
\end{array}\right] \\
& \Delta_{1}=\left[\begin{array}{ll}
\mathrm{Am} 245 & \varepsilon \text { ASP, 245 } \\
\mathrm{Am}, 275 & \varepsilon \text { ASP, 275 }
\end{array}\right] \\
& \Delta_{2}=\left[\begin{array}{ll}
\varepsilon \text { ATR, } 245 & \text { Am245 } \\
\varepsilon \text { ATR, } 275 & \text { Am275 }
\end{array}\right]
\end{aligned}
$$

By applying Cramer's matrix rule the concentration of ATR, EZT and FNF can be found by

$$
\begin{aligned}
& \mathrm{C}_{\mathrm{ART}}=\Delta_{1} / \Delta \\
& \mathrm{C}_{\mathrm{ASP}}=\Delta_{2} / \Delta
\end{aligned}
$$

\section{Validation of the Spectrophotometric method ${ }^{17,18}$ Linearity and Range}

The linearity of an analytical procedure is its ability (within a given range) to obtain test results which are directly proportional to the concentration (amount) of analyte in the sample. The range of an analytical procedure is the interval between the upper and lower concentration (amounts) of analyte in the sample (including these concentrations) for which it has been demonstrated that the analytical procedure has a suitable level of precision, accuracy and linearity.

For LRC and CRM, the absorbances were linear over the range of $4 \mu \mathrm{g} / \mathrm{ml}$ to $20 \mu \mathrm{g} / \mathrm{ml}$ for ATR and over the range of $20 \mu \mathrm{g} / \mathrm{ml}$ to $120 \mu \mathrm{g} / \mathrm{ml}$ for ASP at $245 \mathrm{~nm}$ and $275 \mathrm{~nm}$ respectively. The average absorbance of each concentration obtained was plotted against the concentration of the analytes.

\section{Precision}

The precision of an analytical procedure expresses the closeness of agreement (degree of scatter) between a series of measurements obtained from multiple sampling of the same homogeneous sample under the prescribed conditions.

Intra-day precision was determined by analysing ATR and ASP for 3 times in the same day and Inter-day precision (ruggedness) was determined by analysing next 3 days at $245 \mathrm{~nm}$, and $275 \mathrm{~nm}$ respectively for LRC and CRM.

\section{Accuracy}

The accuracy of an analytical procedure expresses the closeness of agreement between the value which is accepted either as a conventional true value or an accepted reference value and the value found. The accuracy of the method was determined by adding known quantities of the analyte (pure drug substances) to the drug product and applying the developed methods to determine the quantity of the drug present in the spiked sample.
Samples were spiked with 50, 100 and 150\% level solutions of the standard and analysed. The experiment was performed in triplicate $(n=3)$. Percent recovery values were reported.

$$
\begin{aligned}
& \text { Amount of Sample Conc. found-Amount of } \\
& \text { Accuracy }=\frac{\text { Test Conc. taken }}{\text { Amount of Standard Conc. added }} \times 100
\end{aligned}
$$

Assay

The commercial marketed formulation containing $10 \mathrm{mg}$ of Atorvastatin and $75 \mathrm{mg}$ of Aspirin was as the sample for the assay. The sample solution were treated in the same manner as the standard solution. The resulting solution was scanned under UV using methanol as blank.

$$
\text { Percent Assay }=\frac{\text { Calculated qty of test sample }(\mathrm{mg})}{\text { Weight of test sample }(\mathrm{mg})} \times 100
$$

\section{RESULTS AND DISCUSSION}

\section{UV-Spectrophotometric method development}

Different Solvents like Water, Methanol, 0.1N Hydrochloric acid and $0.1 \mathrm{~N}$ Sodium hydroxide were employed for the optimization of the method. Methanol gave a single distinct peak with good absorbance for both the drugs i.e., ATR and ASP. So, it was employed as the solvent. From trial and error method, the $\lambda_{\max }$ of ATR and ASP bulk drugs were determined in methanol by UV spectrophotometer and absorption maximum was found at $245 \mathrm{~nm}$ and $275 \mathrm{~nm}$ respectively. The calibration curves of the drugs were presented in Figure 3 and 4 . The abosrbances of the drugs at respective wavelengths were presented in Table 1.

\section{Linear Regression Analysis (LRC)}

The data obtained from the UV-spectrophotometric method were employed in this Chemometric design.

Conversion of equation into matrix form:

$$
\begin{gathered}
{\left[\begin{array}{l}
\text { Amix1-axyz1 } \\
\text { Amix } 2-\text { axyz2 }
\end{array}\right]=\left[\begin{array}{ll}
\text { bx1 } & \text { by } 1 \\
\text { bx2 } & \text { by } 2
\end{array}\right] \times\left[\begin{array}{l}
\mathrm{Cx} \\
\mathrm{Cy}
\end{array}\right]} \\
{\left[\begin{array}{l}
0.987-0.0359 \\
0.808-0.0035
\end{array}\right]=\left[\begin{array}{l}
0.0392-0.0074 \\
0.0249-0.0074
\end{array}\right] \times\left[\begin{array}{l}
\mathrm{Cx} \\
\mathrm{Cy}
\end{array}\right]} \\
{\left[\begin{array}{l}
0.9511 \\
0.8045
\end{array}\right]=\left[\begin{array}{l}
0.0392-0.0074 \\
0.0249-0.0074
\end{array}\right] \times\left[\begin{array}{l}
\mathrm{Cx} \\
\mathrm{Cy}
\end{array}\right]} \\
{\left[\begin{array}{l}
\mathrm{Cx} \\
\mathrm{Cy}
\end{array}\right]=\left[\begin{array}{l}
0.0392-0.0074 \\
0.0249-0.0074
\end{array}\right] \times\left[\begin{array}{l}
0.9511 \\
0.8045
\end{array}\right]} \\
{\left[\begin{array}{l}
\mathrm{Cx} \\
\mathrm{Cy}
\end{array}\right]=\left[\begin{array}{c}
69.93-69.93 \\
-235.305-370.44
\end{array}\right] \times\left[\begin{array}{l}
0.9511 \\
0.8045
\end{array}\right]} \\
{\left[\begin{array}{l}
\mathrm{Cx} \\
\mathrm{Cy}
\end{array}\right]=\left[\begin{array}{l}
10.252 \\
74.22
\end{array}\right]}
\end{gathered}
$$

By applying linear regression method, the concentration of ATR and ASP was found to be $10.252 \mu \mathrm{g} / \mathrm{ml}$ and $74.22 \mu \mathrm{g} / \mathrm{ml}$. The concentration of Atorvastatin $\left(\mathrm{C}_{\mathrm{x}}\right)$ and Aspirin $\left(\mathrm{C}_{\mathrm{y}}\right)$ present in the given formulation sample were found to be $10.252 \mu \mathrm{g} / \mathrm{ml}$, and $74.22 \mu \mathrm{g} / \mathrm{ml}$ respectively. 
Table 1: Linearity data of Atorvastatin and Aspirin

\begin{tabular}{cccccc|}
\hline & Atorvastatin & \multicolumn{3}{c|}{ Aspirin } \\
\hline Conc. $(\mu \mathrm{g} / \mathrm{ml})$ & Abs at 245 $\mathrm{nm}$ & Abs at 275 $\mathrm{nm}$ & Conc. $(\mu \mathrm{g} / \mathrm{ml})$ & Abs at $245 \mathrm{~nm}$ & Abs at $275 \mathrm{~nm}$ \\
\hline 04 & 0.149 & 0.090 & 20 & 0.176 & 0.149 \\
08 & 0.303 & 0.187 & 40 & 0.321 & 0.299 \\
12 & 0.458 & 0.286 & 60 & 0.470 & 0.431 \\
16 & 0.620 & 0.392 & 80 & 0.622 & 0.597 \\
20 & 0.774 & 0.486 & 100 & 0.735 & 0.726 \\
& & & 120 & 0.928 & 0.890 \\
\hline
\end{tabular}

Table 2: Linearity and Range of Atorvastatin and Aspirin

\begin{tabular}{|c|c|c|c|c|}
\hline \multirow{2}{*}{$\begin{array}{c}\text { Linear } \\
\text { equation } \\
\text { parameters }\end{array}$} & \multicolumn{2}{|c|}{ For LRC method } & \multicolumn{2}{|c|}{ For Cramer's matrix method } \\
\hline & $\begin{array}{c}\text { ATR at } 245 \\
\mathrm{~nm}\end{array}$ & $\begin{array}{c}\text { ASP at } 275 \\
\mathrm{~nm}\end{array}$ & $\begin{array}{c}\text { ATR at } 245 \\
\mathrm{~nm}\end{array}$ & $\begin{array}{c}\text { ASP at } 275 \\
\mathrm{~nm}\end{array}$ \\
\hline $\begin{array}{l}\text { Linear } \\
\text { equation }\end{array}$ & $\begin{array}{c}y=0.0392 x \\
+0.0093\end{array}$ & $\begin{array}{c}y=0.0074 x+ \\
0.0001\end{array}$ & $\begin{aligned} y & =0.0392 x \\
& +0.0093\end{aligned}$ & $\begin{array}{c}y=0.0074 x+ \\
0.0001\end{array}$ \\
\hline $\mathrm{R}^{2}$ & 0.9999 & 0.9991 & 0.9999 & 0.9991 \\
\hline Range & $4-20 \mu \mathrm{g} / \mathrm{ml}$ & $20-120 \mu \mathrm{g} / \mathrm{ml}$ & $4-20 \mu \mathrm{g} / \mathrm{ml}$ & $20-120 \mu \mathrm{g} / \mathrm{ml}$ \\
\hline \multicolumn{3}{|c|}{ Acceptance criteria for $\mathrm{R}^{2}$ value } & \multicolumn{2}{|c|}{ Not less than 0.999} \\
\hline
\end{tabular}

Table 3: Precision data of Atorvastatin and Aspirin

\begin{tabular}{|c|c|c|c|}
\hline \multirow{2}{*}{ Sample } & \multirow{2}{*}{$\begin{array}{l}\text { Concentration } \\
(\mu \mathrm{g} / \mathrm{mL})\end{array}$} & $\begin{array}{c}\text { Intra-day } \\
\text { precision }(n=3)\end{array}$ & $\begin{array}{c}\text { Inter-day } \\
\text { precision }(n=3)\end{array}$ \\
\hline & & $\%$ RSD & $\%$ RSD \\
\hline \multirow{3}{*}{$\begin{array}{l}\text { ATR at } \\
245 \mathrm{~nm}\end{array}$} & 8 & 1.84 & 1.21 \\
\hline & 12 & 1.26 & 1.52 \\
\hline & 16 & 1.13 & 0.72 \\
\hline \multirow{3}{*}{$\begin{array}{l}\text { ASP at } \\
275 \mathrm{~nm}\end{array}$} & 40 & 1.00 & 0.84 \\
\hline & 60 & 0.69 & 0.81 \\
\hline & 80 & 0.67 & 0.98 \\
\hline \multicolumn{2}{|c|}{ Acceptance criteria } & \multicolumn{2}{|c|}{ \% R.S.D $<2.0$} \\
\hline
\end{tabular}

Table 5: Percentage Assay data of Atorvastatin and Aspirin by LRC method

\begin{tabular}{ccc}
\hline \multirow{2}{*}{ Drug } & For LRC method & For CRM method \\
\cline { 2 - 3 } & \% Assay & $\%$ Assay \\
\hline \multirow{2}{*}{ ATR } & 102.52 & 101.62 \\
ASP & 98.9 & 98.84 \\
& Acceptance criteria & $95-105 \%(\mathrm{w} / \mathrm{w})$ \\
\hline
\end{tabular}

\section{Cramer's matrix method (CRM)}

By substituting the values in matrix and solved and each compound was determined by solving the following operations $(\Delta=$ Determinant value of matrix)

$$
\begin{aligned}
& \Delta=\left[\begin{array}{ll}
0.0381 & 0.0077 \\
0.0238 & 0.007462
\end{array}\right] \\
& \Delta_{1}=\left[\begin{array}{ll}
0.987 & 0.0077 \\
0.808 & 0.007462
\end{array}\right]
\end{aligned}
$$

Table 4: Accuracy data of Atorvastatin and Aspirin by LRC and CRM methods

\begin{tabular}{cccc}
\hline \multirow{2}{*}{ Drug } & Percentage & For LRC method & For CRM method \\
\cline { 3 - 4 } & $50 \%$ & \% recovery & \% recovery \\
\hline \multirow{3}{*}{ ATR } & $100 \%$ & 100.10 & 102.5 \\
& $150 \%$ & 101.81 & 102.65 \\
& $50 \%$ & 101.12 & 100.33 \\
\multirow{2}{*}{ ASP } & $100 \%$ & 101.15 & 101.15 \\
& $150 \%$ & 99.95 & 99.95 \\
\multirow{2}{*}{ Acceptance Criteria } & 100.9 & 100.9 \\
\hline \multicolumn{2}{c}{} \\
\hline
\end{tabular}

$$
\Delta_{2}=\left[\begin{array}{ll}
0.0381 & 0.987 \\
0.0238 & 0.808
\end{array}\right]
$$

By applying Cramer's matrix rule the concentration of ATR and ASP were found as follows

$$
\begin{gathered}
\mathrm{C}_{\text {ATR }}=\Delta_{1} / \Delta=0.001084 / 0.00010=10.8 \mu \mathrm{g} / \mathrm{mL} \\
\mathrm{C}_{\mathrm{ASP}}=\Delta_{2} / \Delta=0.00729 / 0.00010=72.9 \mu \mathrm{g} / \mathrm{mL}
\end{gathered}
$$

The concentration of Atorvastatin and Aspirin present in the given formulation sample were found to be $10.8 \mu \mathrm{g} / \mathrm{ml}$, and $72.9 \mu \mathrm{g} / \mathrm{ml} \mathrm{respec-}$ tively.

\section{Method Validation Parameters}

The proposed spectrophotometric method was found to be linear and the data is presented in the Table 2 . The linearity curves were shown in Graph 1and 2. The intra-day and inter-day precision values for both the chemometric designs were presented in Table 3. Accuracy was performed in terms of the Percent recovery values and the values for Atorvastatin and Aspirin by both the chemometric designs were presented in Table 4. The assay of the commercial formulation of the drugs were performed and their percentage assay values were presented in Table 5. 


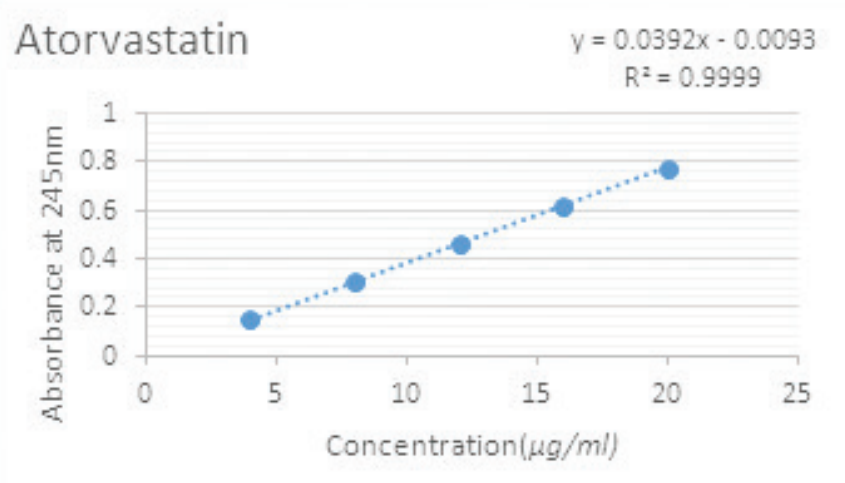

Graph 1: Linearity curve of Atorvastatin

\section{CONCLUSION}

Two simple, accurate, precise, economical methods were developed and validated to estimate Atorvastatin and Aspirin in bulk and Capsule dosage form. The developed methods were simple, economical, statistically evaluated and can be utilized for routine analysis in quality control laboratories. Application of Chemometric techniques helps in complete investigation of data present in the entire spectra for accurate estimation and minimization of error.

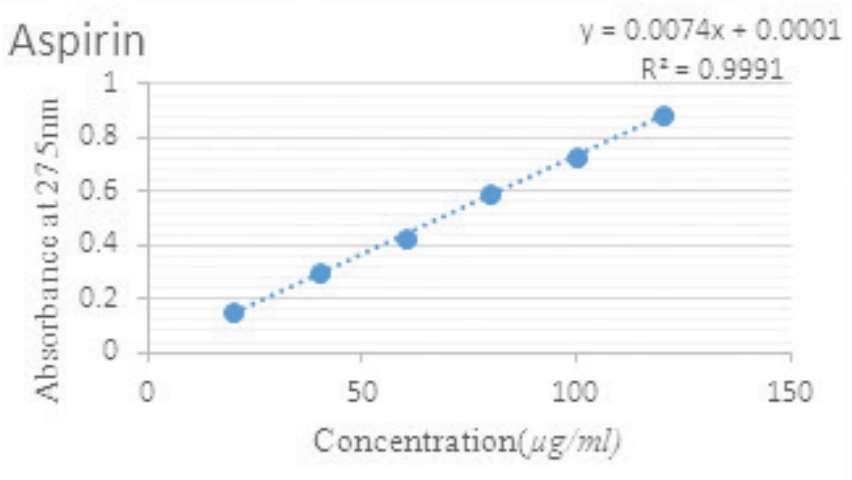

Graph 2: Linearity curve of Aspirin

\section{ACKNOWLEDGEMENT}

We acknowledge the management and the principal of Sri Padmavathi School of Pharmacy, Tiruchanoor, for providing the facilities to carry out this research work. We also acknowledge M/s Vance \& Health, Pharmaceuticals, Pvt. Ltd, Hyderabad for providing the gift samples of the drugs.

\section{CONFLICT OF INTEREST}

This is a non-funding research work. There were no conflicts of interest.

\section{ABBREVIATIONS USED}

AR: Analytical Reagent; ASP: Aspirin; ATR: Atorvastatin; Conc.: Concentration; CRM: Crammer's Matrix Method; HMG CoA-3: Hydroxy-3-Methyl-GlutartylCo-Enzyme A; HPLC: High Performance Liquid Chromatography; LRC: Linear Regression Component; R²: Correlation Coefficient; RSD/R.S.D: Relative Standard Deviation; UV: Ultra-Violet; $\lambda_{\max }$ : Wavelength of Maximum Absorbance.

\section{ABOUT AUTHORS}

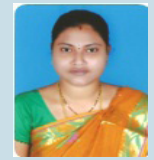

Keerthisikha Palur: Is presently working as Assistant Professor in Department of Pharmaceutical Analysis at Sri Padmavathi School of Pharmacy, Tiruchanoor. She is pursuing her Doctoral degree at Sri Padmavathi MahilaViswa Vidyalayam, Tirupati. Her doctoral research work is focused on Analytical method development and validation.

Bharathi Koganti: Is a Professor of Pharmaceutical Chemistry at the Institute of Pharmaceutical Technology, Sri Padmavathi MahilaViswa Vidyalayam, Tirupati. Her areas of interest include drug designing, urolithiasis, nephron-protective, and peptidomimetics. Presently she is positioned as Director of Distance Education, Sri Sri Padmavathi Mahila Viswa Vidyalayam.

\section{REFERENCES}

1. Matero S. Chemometric methods in pharmaceutical tablet development and manufacturing unit operations. Finalnd: Publications of the University of Eastern Finland: 2010. 5-12.

2. Mike. J. Adams. Chemometrics in Analytical Spectroscopy. United Kingdom: Royal society of chemistry; 1995. 155-97.

3. Naveen K, Ankit B, Sarma GS and Ravindra KR. Chemometrics tools used in analytical chemistry: An overview. Talanta. 2014;(123):186-99.

4. Miller J.N., Miller J.C. Statistics and Chemometrics for analytical chemistry. 6th ed. U.S.A:Pearson Education Limited; 2010. 52-8.

5. El-GindyAlaa, Ghada MH. Chemometrics in Pharmaceutical Analysis: An Introduction, Review, and Future Perspectives. J AOAC Int. 2012;95(3):609-23.

6. Erdal Dinc. Linear regression analysis and its application to themultivariate spectral calibrations for the multiresolution of a ternary mixture of caffeine paracetamol and metamizol in tablets. J Pharm Biomed Anal. 2003:33(4):605-15.

7. Pawar HA, Kamat SR. Chemometrics and its Application in Pharmaceutical Field. J Phys Chem Biophys. 2014;4(6):1000169.

8. Brown AM. A step-by-step guide to non-linear regression analysis of experi- mental data using a Microsoft Excel spreadsheet. Comput. Methods Programs Biomed. 2001;65(3):191-200.

9. Drugbank.ca [home page on internet].Canada: Canadian Institutes of Health Research. Available from: http://www.drugbank.ca/drugs/DB01076. 6.Drugbank. ca [home page on internet] Canada: Canadian Institutes of Health Research.

10. Drugbank.ca [home page on internet]. Canada: Canadian Institutes of Health Research. Available from: http://www.drugbank.ca/drugs/DB00945.

11. Pawar PY, Ankita RB, Sonu RL, Amruta AB. Simultaneous estimation of atorvastatin calcium and aspirin in pure and capsule dosage form by using U.V. spectrophotometric method. Der Pharma Chemica. 2013;5(3):98-103.

12. Hirave RV, Bendgude RD, Maniyar MG, Kondawar MS, Patil SB. Spectrophotometric method for Simultaneous estimation of Atorvastatin Calcium \& Fenofibrate in tablet Dosage Form. Int J Drug Dev \& Res. 2013;5(1):38-42.

13. Ray CD, Basu A, Chakraborty M, Chakraborty S. Analytical Method Development and Validation of Simultaneous Determination of Atorvastatin Calcium and Aspirin in Capsule Dosage form by RP-HPLC. Int J Pharm Innovations. $2011 ; 5(1): 39-48$ 
14. Londhe SV, Deshmukh RS, Mulgund SV, Jain KS. Development and Validation of a Reversed-phase HPLC Method for Simultaneous Determination of Aspirin, Atorvastatin Calcium and Clopidogrel Bisulphate in Capsules. Indian J Pharm Sci. 2011;73(1):23-9.

15. Patole SM, Potale LV, Khodke AS, Damle MC. A validated HPLC method for analysis of Atorvastatin calcium, Ramipril and Aspirin as the bulk drug and in combined capsule dosage forms. Int J Pharm Sci Rev \& Res. 2010;3(4):40-5.

16. Sankar AS, Vetrichelvan T, Venkappaya D. Simultaneous estimation of ramipril, acetylsalicylic acid and atorvastatin calcium by chemometrics assisted UVspectrophotometric method in capsules. Acta Pharm. 2011;61(3):283-96.

17. Pawar AKM, Nageswara Rao ABN, Gowri Sankar D. Simultaneous Estimation of Enalapril Maleate, Hydrochlorothiazide, Aspirin and Atorvastatin in pure and its Simulated Dosage form Using Isocratic RP-HPLC. Der Pharmacia Lettre. 2011;3(6):58-67.

18. H. O. Kaila HO, Ambasana MA, Shah AK. A Simple and Rapid Ultra-Performance Liquid Chromatographic Assay Method for the Simultaneous determination of Aspirin, ClopidogrelBisulphate and Atorvastatin Calcium in Capsule Dosage
Form. Int J Chem Tech Res. 2011;3(1):459-65.

19. Archita Patel and Chhaya Macwana. Simultaneous Determination of Atorvastatin Calcium, Ezetimibe and Fenofibrate in a Tablet Formulation by HPLC. J AOAC Int. 2012;95(2):419-23.

20. Ankit A, Shrikalp D, Pranav P, Keyur P, Sagar S and Kinjal R. Reverse phase high performance liquid chromatographic (HPLC) method for simultaneous determination of atorvastatin, ezetimibe and fenofibrate in Commercial tablets. Int J Pharm \& Pharmaceutical Sci. 2012;4(1):206-9.

21. Lakshmi KS, Lakshmi S. Design and Optimization of a Chemometric-Assisted Spectrophotometric Determination of Telmisartan and Hydrochlorothiazide in Pharmaceutical Dosage Form. J Young Pharm. 2010;2(1):85-9.

22. ICH, Q2 (R1) validation of analytical procedure, text and methodology. International conference on Harmonization, November; 1996.

23. International Conference on Harmonization $(\mathrm{ICH})$ of technical requirements for registration of pharmaceuticals for human use: Validation of analytical procedures. Text and methodology Q2 (R1); 2005 